\title{
Do Alternative Measures of GDP Affect Its Interpretation?
}

\author{
Bart Hobijn and Charles Steindel
}

Gross domestic product's high correlation with unemployment and inflation makes it a key measure of the U.S. economy. Yet the somewhat arbitrary nature of the GDP construction process complicates interpretation and measurement of the indicator. A study of an alternative measure of GDP designed to address the published series' limitations finds that the adjusted measure differs in its representation of the long-term trend-but not the short-term fluctuations - of GDP. The published series'relevance as an indicator is therefore robust to some of the arbitrariness of its construction.

0 n October 31, 2009, the U.S. Bureau of Economic Analysis (BEA) announced that real gross domestic product, or GDP, had grown at a 3.5 percent annual rate in the third quarter. Because the reported increase was the first in more than a year, many observers regarded the news as a sign that the recession had ended.

Unaddressed in the commentary, however, was a fundamental question: What does GDP measure? The standard answer is that it measures the "size" of the U.S. economy. The economy is in some basic sense larger if real, or inflation-adjusted, GDP has increased. That response begs an important related question: How is size defined? Alaska is larger than Rhode Island if our unit of measurement is land area, but Rhode Island is larger if our measure is population. Gauging the size of a state is not a straightforward task, and the method depends heavily on what the information is used for. Comparably, the U.S. economy can be measured across any number of dimensions.

GDP is in many ways the central measure of an economy. For example, the faster the growth in real GDP, the faster the growth in jobs. Although the relationship between the measure and inflation is more tenuous, it is generally acknowledged that if the level of real GDP exceeds that of potential real GDP, inflation will increase. ${ }^{1}$ The ability to forecast GDP, and to understand how policy influences the series, is therefore of critical importance to the formulation of monetary and fiscal policy. These considerations make it all the more important to assess the limitations of the GDP measure and to examine possible alternatives.

This edition of Current Issues describes the major aspects of GDP and demonstrates how alterations to them can affect our view of the economy. Specifically, we construct an alternative measure of real GDP that differs from the standard series by expanding the scope of economic activity included. This alternative measure exhibits a different long-term trend than the published series, but it would likely be no more

${ }^{1}$ Potential GDP is an estimate of the amount of real GDP the economy can produce if capital and labor are fully and efficiently used. 
reliable than the existing figure as an indicator of short-term momentum in the economy.

\section{The Importance of GDP as an Indicator}

GDP, especially real GDP, is considered the central measure of overall economic activity primarily because its long- and shortrun movements are correlated with many factors of interest to economists and policymakers alike. An important example is the close association over the long run between real GDP growth and the growth of real, or inflation-adjusted, income, and thus the improvement in living standards. Another is the close correlation between GDP growth measured in current dollars (that is, GDP growth before correcting for inflation) and the long-run growth of the tax base, and thus of tax revenues.

The associations between real GDP and employment and inflation are also of significance. The Federal Open Market Committee is mandated by statute to attempt to achieve "maximum employment" and "stable prices"; therefore, it is not surprising that examinations of trends in real GDP are critical to monetary policymaking. Two of the most commonly studied short-run relationships that associate real GDP with employment and with inflation are Okun's law and the Phillips curve, respectively.

Okun's law is shorthand for the relationship between real GDP growth and changes in the unemployment rate (Chart 1$)^{2}$ The top panel of the chart shows that unemployment generally decreases when real GDP grows fast and vice versa. The long-term historical correlation between these variables is -.70 — suggesting a strong tendency for the unemployment rate to fall in association with an increase in real GDP growth. However, this negative correlation has become quite variable over the last twenty years; indeed, at times the correlation has been positive (bottom panel). There have been periods of some years when the unemployment rate appears to have risen as real GDP strengthened.

The Phillips curve describes the relationship between GDP and inflation (Chart 2). ${ }^{3}$ Here, real GDP is not measured in terms of its growth rate, but rather in the deviation from its level of potential, as estimated by the Congressional Budget Office. This deviation is known as the output gap. Historically, inflation has tended to be higher (than its moving average) when output is above potential GDP and vice versa. The correlation between inflation and the output gap, however, is not as robust as the one between the unemployment rate and real GDP growth. In several periods, such as the second half of the 1990s, inflation and the output gap diverged. For example, in the late 1990s, real GDP was reported to be higher than potential while inflation was ebbing.

\footnotetext{
${ }^{2}$ The term honors the late Arthur Okun, who emphasized the rule-of-thumb relationship between the percentage point rate of real GDP growth and the percentage point change in the unemployment rate.

${ }^{3}$ The original relationship, described in Phillips (1958), was between the unemployment rate and wage growth for the United Kingdom.
}

Chart 1

\section{Okun's Law}
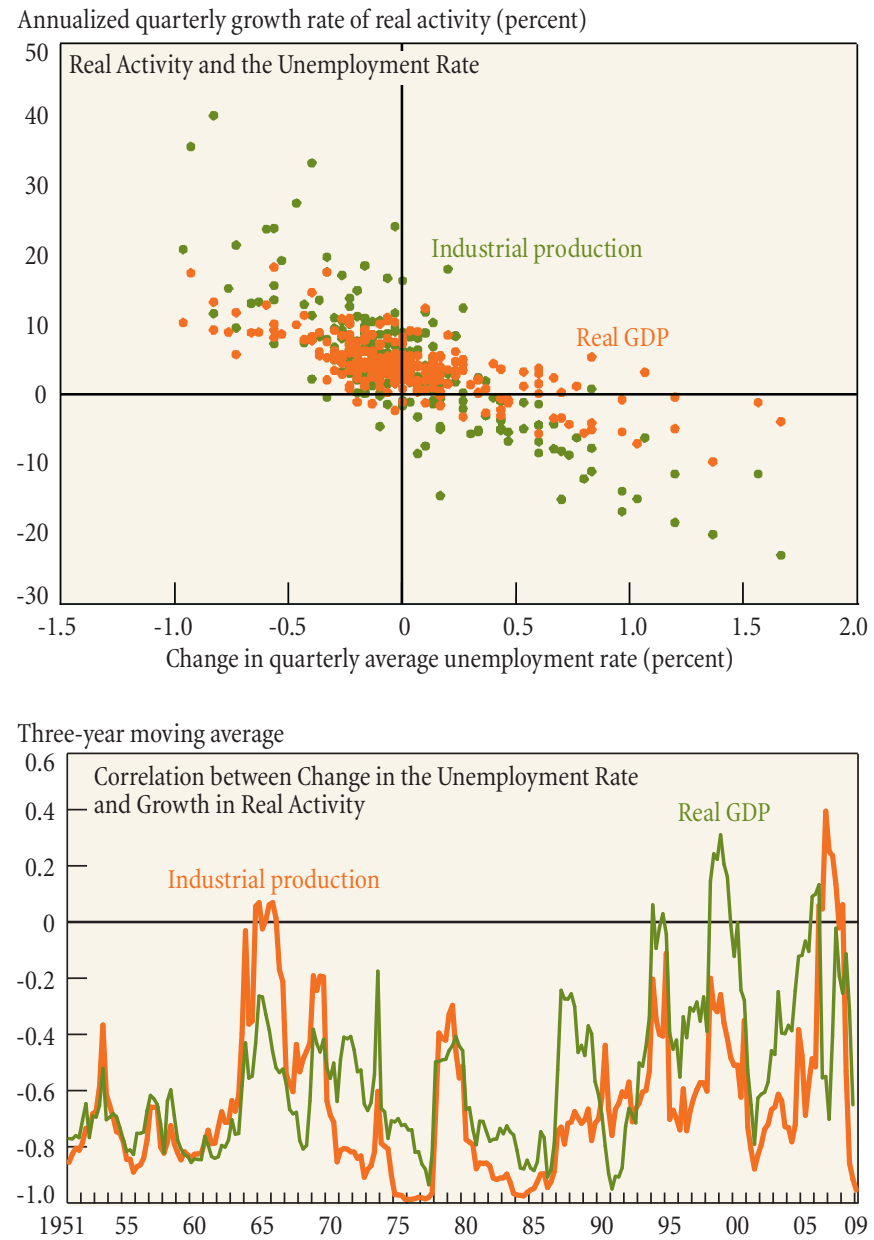

Sources: U.S. Department of Commerce, Bureau of Economic Analysis; U.S. Department of Labor, Bureau of Labor Statistics; Board of Governors of the Federal Reserve System.

\section{The Concept of GDP}

As the preceding discussion makes clear, the real GDP measure is a gauge of overall economic activity that co-moves with other key variables, making the quarterly measure the focus of intense scrutiny. While GDP is clearly a very practical series to follow, its use does raise questions, such as whether the indicator effectively measures what it is intended to and whether alternative gauges of aggregate activity can provide comparable information about other economic variables. To explore these issues, we revisit the basic concept of what GDP is intended to measure and how well it succeeds.

Three commonly used undergraduate textbooks in economics provide the following definitions of GDP:

- "The market value of an economy's domestically produced goods and services over a specified period of time" (Barro 2008). 


\section{The Phillips Curve}

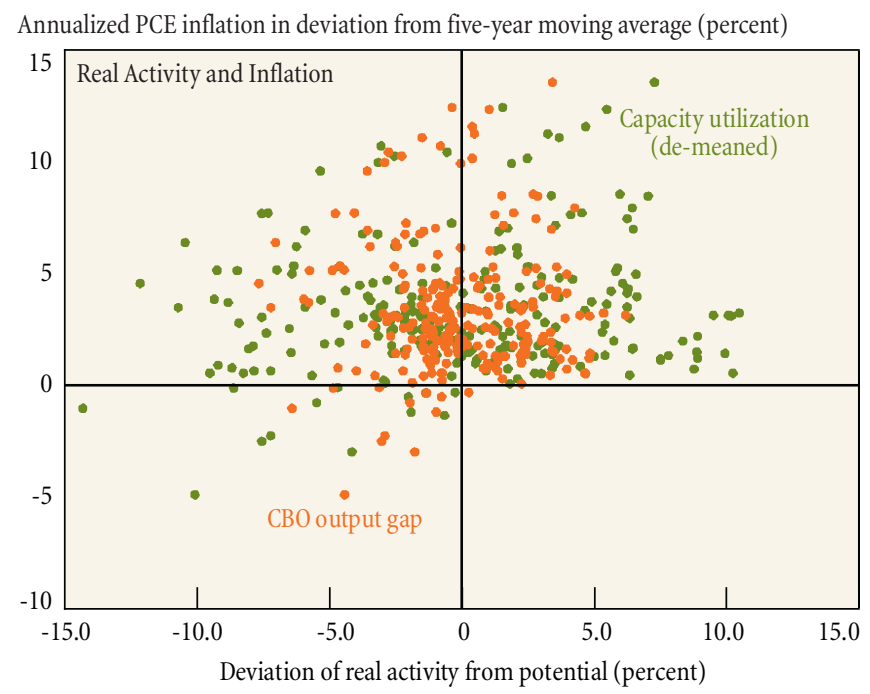

Three-year moving average

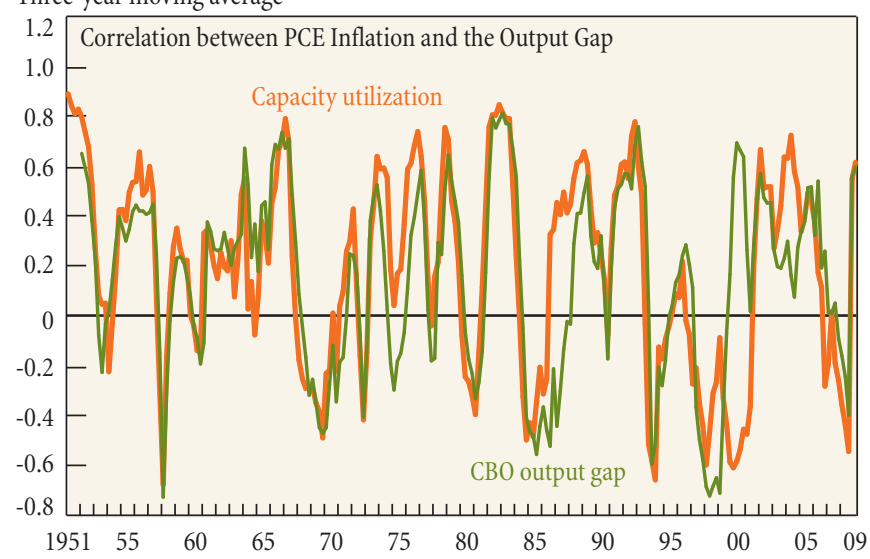

Sources: U.S. Department of Commerce, Bureau of Economic Analysis; Congressional Budget Office (CBO); Board of Governors of the Federal Reserve System.

Note: The inflation measure used is the personal consumption expenditures (PCE) price index.

- "The market value of final goods and services newly produced within a country's borders within a fixed time period" (Abel, Bernanke, and Croushore 2008).

- "The dollar value of final output produced during a given period of time within the borders of the United States" (Williamson 2008).

These definitions share four components: GDP reflects 1) a market/dollar value of 2) final goods (and services) produced 3) within the borders of the United States 4) in a particular time period. However, defining each of these components is not as straightforward as it seems.
The fourth component is the easiest to define. An estimate of U.S. GDP is released for every quarter of the year by the BEA. ${ }^{4}$ The "particular time period" is therefore a quarter.

Because the borders of the United States are well defined, the third component seems uncontroversial. However, this is not always true. The main issue here is how to account for returns from sales abroad by American firms that are partly generated as a result of activity in the United States. What fraction of such sales should be counted as output produced in the United States? ${ }^{5}$

The other two components of the definition of GDP have generated the most debate; we consider each in more detail.

\section{Final Goods Production}

The value of production, by definition, equals the value of sales. However, in a period as long as one quarter, it is likely that some products are sold more than once. For instance, a chip sold to a computer maker, which sells the computer a few days later, is in effect sold twice during a quarter. Here, it makes no sense to view quarterly GDP as the sum of all sales by all sellers; the chip produced would be double-counted.

The BEA adjusts GDP for such double-counting by subtracting the sales of goods and services that are then used in the same quarter to make other products. These goods and services-such as the computer chip-are known as intermediate inputs.

The argument for the exclusion of intermediate inputs by extension suggests that goods or services sold to consumers for immediate use, or sold to governments for immediate provision to consumers, properly belong in GDP. These goods and services contribute directly to the welfare of the nation's households.

A very large portion of GDP, however, involves the production and sale of other products, including consumer durable goods, business inventory investment, home construction, businesses' fixed capital expenditures, government capital spending, and exports. These products either provide their benefits to households gradually over time or generate income that can be used to purchase items in the future.

The justification for including these products, whose welfare value differs markedly from that of immediate consumption, in GDP is that in many instances their sale adds to the wealth of the population. A traditional definition of income is "consumption plus saving." If saving is equated to wealth accumulation, and wealth accumulation to sales of the types of products described above, GDP would fit this definition of income (the box discusses the relationship between GDP and aggregate income).

\footnotetext{
${ }^{4}$ Landefeld, Seskin, and Fraumeni (2008) offer a detailed description of the GDP release and the source data used.

${ }^{5}$ See McGrattan and Prescott (2008) for a formal theoretical analysis of this measurement issue.
} 


\section{GDP and Aggregate Income}

If intermediate inputs are excluded from estimates of aggregate output, aggregate output will equal aggregate income (the cost of intermediate inputs is subtracted from sales when businesses compute their earnings). In principle, aggregate income can be observed by adding the incomes of all households and businesses, a calculation that corresponds in concept to the national income series published alongside GDP. Indeed, the oldest measure of economic activity is the national income series, not GDP. ${ }^{\mathbf{a}}$ The two series move more or less in tandem. Because most government taxes are based on various types of income, it is not surprising that swings in aggregate government revenue are closely linked to moves in GDP. Moreover, because households earn the majority of incomes, aggregate household income is strongly connected to GDP.

Given the simplicity of the national income concept, what is the need for the more elaborate GDP concept and measure? Aside from the practical difficulties of collecting income data on a timely basis, ${ }^{\mathbf{b}}$ there is the issue of deflating the current-dollar income figure to derive the critical measures of price-adjusted, or real, income and output. This deflation can only be conducted if there is information available on the distribution of production and prices, not only on current-dollar income.

\footnotetext{
${ }^{\text {a }}$ See Landefeld, Seskin, and Fraumeni (2008) for a brief history of the U.S. National Income and Product Accounts.
}

b Income measures ultimately rely on data collected for tax purposes, and it can take a very long time to compile definitive aggregate figures.

However, purchases of capital goods, business inventories, and consumer durables, as well as home construction, do not square all that well with wealth accumulation. First of all, the lion's share of these purchases is used for replacement-in effect, the purchases are made to preserve wealth, not to add to it. While it is true that there are estimates of the loss of value as these types of products age or are destroyed prematurely by natural and other disasters, and one could focus on GDP minus these estimates, such estimates are imperfect.

Another difficulty is defining precisely what should be included in capital goods. A capital good in principle is an intermediate input that is used up only gradually rather than all at once. Thus, the distinction between capital inputs and intermediate inputs is, to some extent, arbitrary.

For example, on the one hand, capital spending was redefined in the GDP data in recent years to include government and business purchases of software from external vendors, which had previously been classified as an intermediate input. On the other hand, research and development (R\&D) spending by business and government continues to be viewed as an intermediate product, even though such spending is intended to help boost future output.
The ambiguities attending the classification of goods as "final" or "intermediate" underscore the difficulty of constructing an appropriate measure of GDP. The criteria used to include certain goods and services may not be entirely consistent or clear-cut.

\section{Market Value}

Economic activity encompasses much more than the production and sale of goods and services in markets. Many other activities require the use of substantial portions of the nation's labor and capital. Households, nonprofit organizations, and governments provide products - most notably, services — that would reap substantial revenues if supplied by private businesses. Among these are a family's care of children and other dependents and the household's work maintaining a home as well as the shelter provided by one's own home. Services provided by the government without sales to users include education, fire protection, and defense. Although assigning a value to these services can be difficult (particularly on a quarterly basis), incorporating estimates of the value of some of these services in the GDP measure is appropriate - not only to make the measure more "complete," but also because failure to do so would mean that shifts of the supply of such activities to and from the private business sector could potentially affect observed GDP growth, thus complicating the interpretation of the data.

This is to say that a large portion of GDP consists of estimates of the value of sales that occur in nonmarket transactions. Indeed, in 2007 more than $\$ 2$ trillion of current-dollar GDP — nearly 15 percent of the total-consisted of estimates of nonmarket activities, or "imputations." 6

Despite the seemingly extraordinary size of nonmarket GDP, it can be argued that not enough of these activities have been included in GDP to make it a true aggregate economic measure. Some substantive types of nonmarket activities are excluded from the series. The best-known example is the value of a family's time spent on child care and home maintenance. The choice of which nonmarket activities to include and exclude is in large part guided by practical considerations about whether data on reasonable proxies for these activities are available on a quarterly basis.

Significantly, while it is hard to account for the value of sales for nonmarket activities, it is even harder to estimate the price of such nonmarket activities. A measure of such prices is necessary for the construction of real GDP. ${ }^{7}$

There are basically two approaches to estimating the real value and price of nonmarket activities. The first is to assume that the quantity of the nonmarket goods and services used grows at the same rate as that of an actual market activity. For example,

\footnotetext{
${ }^{6}$ The current-dollar value of services supplied by governments is part of GDP, but it is not considered "imputed."

${ }^{7}$ Steindel (1995) discusses how price and real output data are used to construct real GDP.
} 
the real value of the shelter services provided to homeowners is typically assumed to be a constant fraction of the real value of the owner-occupied housing stock.

The second approach is to assume that the price of the nonmarket goods and services is a weighted average of the price of the inputs used to produce them (including in these input prices the wages of workers employed in these tasks). This approach is used to price government consumption expenditures and investment relating to, say, education and defense services. The method assumes no productivity growth in the production of these goods and services. However, because there is positive productivity growth in the production of comparable market-based services, the assumption of no government productivity growth probably underestimates the growth of real government expenditures.

In sum, although the conceptual basis of GDP is fairly straightforward, practical construction of the measure requires numerous modifications that give it something of an arbitrary nature. Indeed, it is difficult to view GDP as a measure of true aggregate sales, because the published series arguably does not adequately account for all sales in markets, such as R\&D expenditures and some key nonmarket activities.

\section{An Alternative Measure of Real GDP Growth}

If the GDP measure were to be adjusted to address some of the issues we have raised, how would the series be affected? To answer this, we construct an alternative measure of GDP that includes 1) an estimate of investment in R\&D and other similar intangible items, 2) an estimate of the fraction of wages paid to women that can be viewed as representing the value of forgone production done in the home, and 3) an assumption that productivity growth in the government sector is the same as it is in the business sector.

Our adjusted GDP series begins in 1983 and, in light of the fact that some adjustments require data available only on an annual basis and with a considerable lag, extends just to $2003 .^{8}$ The limited nature of the data means that our adjustments will be based on some very elementary assumptions. ${ }^{9}$

Our first adjustment is the inclusion of the investments in intangible capital reported by Corrado, Hulten, and Sichel (2006). Because in real terms these investments have grown faster than published GDP, inclusion of the investments would add about 0.4 percentage point on average to the growth rate of real GDP during the sample period (see table, column 2).

The second adjustment accounts for the effect of higher female labor force participation. The increased participation partly reflects a shift from the nonmarket activity of production in the

\footnotetext{
${ }^{8}$ In addition, note that we are using data available prior to the BEA's July 31, 2009, release of a comprehensive revision of the GDP data.

${ }^{9}$ These assumptions are described in the online appendix to this article, available at $<$ http://www.newyorkfed.org/research/current_issues/ci15-7_appendix.pdf $>$.
}

\section{Published and Adjusted Growth Rates of Real GDP}

\begin{tabular}{|c|c|c|c|c|c|}
\hline \multirow[b]{2}{*}{ Year } & \multirow[b]{2}{*}{$\begin{array}{l}\text { Published } \\
\text { GDP } \\
(1)\end{array}$} & \multicolumn{3}{|c|}{ Adjustments } & \multirow[b]{2}{*}{$\begin{array}{l}\text { Adjusted } \\
\text { GDP } \\
(5)\end{array}$} \\
\hline & & $\begin{array}{c}\text { Intangibles } \\
\text { (2) }\end{array}$ & $\begin{array}{c}\text { Forgone } \\
\text { Production } \\
\text { in the Home } \\
\text { (3) }\end{array}$ & $\begin{array}{c}\text { Government } \\
\text { Productivity } \\
\text { Growth } \\
\text { (4) }\end{array}$ & \\
\hline 1983 & 4.5 & 0.4 & 0.3 & 0.8 & 6.0 \\
\hline 1984 & 7.2 & 0.6 & -0.1 & 0.5 & 8.2 \\
\hline 1985 & 4.1 & 0.8 & -0.1 & 0.1 & 4.9 \\
\hline 1986 & 3.5 & 0.3 & -0.1 & 0.3 & 4.0 \\
\hline 1987 & 3.4 & 0.2 & -0.1 & 0.0 & 3.5 \\
\hline 1988 & 4.1 & 0.4 & -0.1 & 0.2 & 4.7 \\
\hline 1989 & 3.5 & 0.4 & 0.1 & 0.0 & 4.0 \\
\hline 1990 & 1.9 & 0.4 & -0.1 & 0.1 & 2.2 \\
\hline 1991 & -0.2 & 0.4 & -0.1 & -0.1 & 0.0 \\
\hline 1992 & 3.3 & 0.1 & -0.1 & 0.5 & 3.7 \\
\hline 1993 & 2.7 & 0.3 & 0.0 & 0.1 & 3.0 \\
\hline 1994 & 4.0 & 0.3 & 0.1 & 0.1 & 4.5 \\
\hline 1995 & 2.5 & 0.6 & 0.0 & 0.0 & 3.1 \\
\hline 1996 & 3.7 & 0.6 & 0.0 & 0.2 & 4.5 \\
\hline 1997 & 4.5 & 0.8 & 0.0 & 0.1 & 5.4 \\
\hline 1998 & 4.2 & 0.5 & -0.3 & 0.2 & 4.6 \\
\hline 1999 & 4.5 & 0.3 & -0.1 & 0.2 & 4.8 \\
\hline 2000 & 3.7 & 0.7 & -0.1 & 0.2 & 4.5 \\
\hline 2001 & 0.8 & -0.2 & 0.0 & 0.0 & 0.5 \\
\hline 2002 & 1.6 & -0.1 & -0.1 & 0.3 & 1.8 \\
\hline 2003 & 2.5 & 0.0 & 0.0 & 0.5 & 3.0 \\
\hline \multicolumn{6}{|c|}{ Meто: } \\
\hline \multicolumn{5}{|c|}{ Correlation of published and adjusted GDP growth rates } & 0.99 \\
\hline
\end{tabular}

Sources: U.S. Department of Commerce, Bureau of Economic Analysis; Corrado, Hulten, and Sichel (2006); author' calculations.

Notes: GDP is gross domestic product. All figures are percentages, except for the correlation in the memo section. The columns are related as follows: $(5)=(1)+(2)+(3)+(4)$.

home to market activities that generate wages. Accordingly, part of the growth of published GDP that is attributable to the growth of female labor inputs occurs at the cost of fewer goods and services produced at home. House, Laitner, and Stolyarov (2008) estimate that the market value of this forgone production in the home is about a quarter of the labor compensation of women. ${ }^{10}$ Using their estimate to correct published real GDP growth, we obtain a 5.4 percent downward adjustment of nominal GDP in 1983 and 6.7 percent downward adjustment in 2003. These adjustments would lead to only small downward adjustments of the growth rate of real GDP, -0.04 percentage point, on average, over our sample (table, column 3 ).

\footnotetext{
10 This estimate is subject to many potential sources of bias, described by the authors. The details of these sources of bias are beyond the scope of our analysis.
} 
Our third adjustment involves real government consumption expenditures and investment. We assume that productivity growth in the sector equals that in the U.S. nonfarm business sector. Our assumption does not affect nominal GDP, but it does affect the computed growth rate of real government spending. This adjustment, on average, adds 0.2 percentage point of real growth to our adjusted measure (table, column 4 ). Our adjustment is probably an overestimate, because a large part of government activities consists of services that are subject to "Baumol's cost disease" (Baumol and Bowen 1966) — that is, productivity growth of these services is likely to be much lower than the productivity growth of the economy's other sectors.

\section{The Two Measures Compared}

Our three adjustments add roughly 0.5 percentage point to annual real GDP growth over the 1983-2003 period. Recall, however, that our adjustments would not change other key economic measures, such as the unemployment rate. We are just enlarging what one would include in both nominal and real economic activity and slightly redefining aggregate economic growth. ${ }^{11}$ We are interested in learning not only how the long-term history of real GDP is affected by these changes, but also whether our redefinitions would affect the short-term swings in real GDP growth that help determine movements in employment and inflation.

Our adjusted measure is found to have little effect on the short-term dynamics of real GDP. The annual growth rate of our measure is closely aligned with the published growth rate of real GDP (table, columns 5 and 1). Moreover, the correlations of both annual time series of GDP growth with changes in the unemployment rate and with PCE inflation are almost identical. ${ }^{12}$ Thus, at an annual frequency, the adjusted and unadjusted GDP series will most likely capture in a similar way the correlations reflected in Okun's law and the Phillips curve. Further, reliance on a GDP series adjusted along the lines we suggest would likely have little effect on the timing of cyclical fluctuations in economic activity. The National Bureau of Economic Research's dating of peaks and troughs in the business cycle is based on economy-wide movements in such variables as employment and production. While the published real GDP series is viewed as a key indicator

\footnotetext{
${ }^{11}$ By redefining the list of goods and services included in both real and nominal GDP, and adjusting the measurement of real GDP slightly relative to that of nominal GDP in a number of sectors, we are changing the levels and growth rate of GDP price measures. In that sense, we are suggesting changes in the history of inflation measures; indeed, because some of our changes would influence the growth of real and nominal consumer spending (unpaid production done in the home would be a component of consumer spending), they would affect the history of the personal consumption expenditures (PCE) price series.

12 The range of the adjusted GDP growth series ( 0 percent to 8.2 percent) is somewhat larger than that of the published series ( -0.2 percent to 7.2 percent); the difference reflects the fairly large and procyclical variation in spending on intangibles as well as cyclical fluctuations in government production. Undoubtedly, careful examination and reestimation of Okun's law and Phillips curve relationships using the transformed GDP data would lead to some modifications of the standard results.
}

of movements in aggregate production in the determination of business cycle turning points (see < http://www.nber.org/cycles/ dec2008.html >), the peaks and troughs in the adjusted series would likely be comparable to those in the published series.

Our assumptions-aside from increasing the scope of activity included in GDP, and thus its size - basically affect the longer run trends in real GDP, but seem to have little impact on the magnitude of the short-run swings crucial for determining moves in employment and inflation. Still, getting the size and long-run trend of GDP "right" is of critical importance in understanding the sources of longer term growth. For instance, an increase in measured GDP growth stemming from the one-time transition of women from nonmarket to market-priced activity - which arguably occurred over the last generation-will have less of an impact on very long-run trends in output and consumption than would an increase in underlying technical progress. (As we observed, if women's nonmarket activities had been credited in the National Income and Product Accounts, the increase in GDP attributable to the shift in their activities would have been muted.)

Another consideration is that published GDP also encompasses assumptions that affect the long-run trend rather than high-frequency movements; an example is the inclusion in GDP of the imputed income earned from home ownership. Much of the construction of quarterly real and nominal GDP involves interpolation from longer term trends rather than the incorporation of newly available information. In contrast, the Federal Reserve's monthly industrial production (IP) index encompasses a large amount of the high-frequency data released on economic activity. ${ }^{13}$

Much of the difference between the IP index and GDP reflects the latter's inclusion of many components that are essentially smooth trends. At a quarterly frequency, the growth rate of the IP index is highly correlated with that of real GDP - as shown in Chart 3 , which plots the quarterly growth rates of real GDP and the IP index over the postwar period. The correlation over the entire sample period is 0.8 . Charts 1 and 2 (bottom panels), respectively, show the equivalent of Okun's law and the Phillips curve for IP growth and the capacity utilization rate (the counterpart of the output gap for IP data). For these relationships, we see little qualitative difference from their GDP counterparts. At times, the link between industrial production and unemployment seems stronger, at other times weaker, than the link between GDP and unemployment. A similar comment can be made about the

\footnotetext{
${ }^{13}$ Industrial production aggregates the output of factories and mines along with utility sales to households. Thus, the domestically produced physical inputs to the goods- and structures-producing portions of GDP are included in industrial production. Goods and structures production are the components of GDP that exhibit the greatest cyclical fluctuation. (A discussion of the construction of the industrial production measures can be found at $<\mathrm{http}: / / \mathrm{www}$.federalreserve.gov/ releases/g17/ip_notes.htm>.) Monthly measures of industry outputs are based on the relationship between monthly indicators and more definitive long-term measures. The key contrast with many of the GDP components is the availability of these reliable monthly indicators.
} 
Chart 3

Real GDP and Industrial Production Growth, 1948-2008

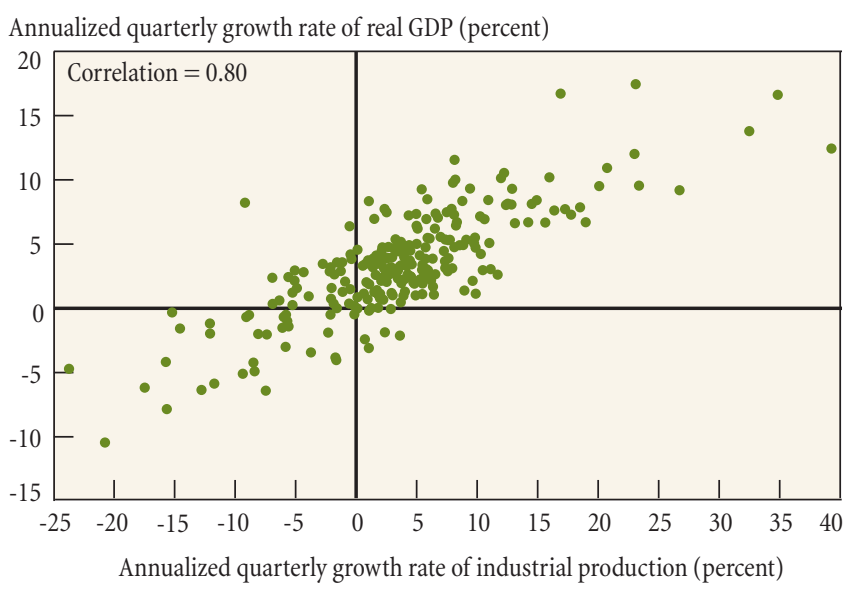

Sources: U.S. Department of Commerce, Bureau of Economic Analysis; Board of Governors of the Federal Reserve System.

relationship between the capacity utilization rate and inflation and the relationship between the output gap and inflation. Needless to say, in any quarter or year, industrial production does not move in lockstep with published real GDP, and either aggregate may at any time be the superior guide to ongoing developments in employment and inflation. However, our results suggest that movements in real GDP are not necessarily better at identifying such developments than are movements in industrial production measures. ${ }^{14}$

\section{Conclusion}

Even though the concept of GDP is straightforward and uncontroversial, the practical interpretation and measurement of the indicator are subject to many limitations. To measure GDP on a quarterly basis, the BEA makes many somewhat arbitrary modifications. Most notably, the BEA estimates and includes in the published measure a considerable amount of nonmarket activity

\footnotetext{
${ }^{14}$ Steindel (2004) discusses the relationship between industrial production and GDP. We do not propose replacing cyclical analysis of GDP with analysis of industrial production. Economic theory and related empirical models are better suited for understanding moves in GDP than moves in industrial production-for instance, GDP movements are clearly connected to movements in aggregate income; the same connection is not as straightforward for industrial production.
}

while excluding substantial amounts of market and nonmarket activity that could plausibly be included.

A large part of what makes the index useful is its high correlation with other measures of aggregate economic outcomes, such as unemployment and inflation, and the reliability of its trend as an indicator of long-run patterns in other variables, such as government revenues. As we have shown, changing many of the assumptions and modifications made to estimate GDP would likely have little effect on the short-term dynamics of the series. Our study therefore suggests that the relevance of GDP as an indicator of ongoing aggregate economic activity is fairly robust to some of the arbitrariness involved in its construction. However, fluctuations in GDP are not the only indicators of short-term movements in aggregate activity; it is arguable that industrial production can provide a useful alternative.

\section{The authors thank Daniel Sichel of the Federal Reserve Board} for the data on intangibles.

\section{References}

Abel, Andrew B., Ben S. Bernanke, and Dean Croushore. 2008. Macroeconomics. 6th ed. Boston, Mass.: Pearson.

Barro, Robert J. 2008. Macroeconomics: A Modern Approach. Mason, Ohio: Thomson South-Western.

Baumol, William J., and William G. Bowen. 1966. Performing Arts: The Economic Dilemma. New York: Twentieth Century Fund.

Corrado, Carol A., Charles R. Hulten, and Daniel E. Sichel. 2006. "Intangible Capital and Economic Growth.” NBER Working Paper no. 11948, January.

House, Christopher, John Laitner, and Dmitriy Stolyarov. 2008. "Valuing Lost Home Production of Dual Earner Couples." International Economic Review 49, no. 2 (May): 701-36.

Landefeld, J. Steven, Eugene P. Seskin, and Barbara M. Fraumeni. 2008. “Taking the Pulse of the Economy: Measuring GDP." Journal of Economic Perspectives 22, no. 2 (spring): 193-216.

McGrattan, Ellen R., and Edward C. Prescott. 2008. “Technology Capital and the U.S. Current Account." Federal Reserve Bank of Minneapolis Staff Reports, no. 406, revised March 2009.

Phillips, Alban W. 1958. “The Relationship between Unemployment and the Rate of Change of Money Wages in the United Kingdom 1861-1957." Economica 25, no. 100 (November): 283-99.

Steindel, Charles. 1995. “Chain-weighting: The New Approach to Measuring GDP” Federal Reserve Bank of New York Current Issues in Economics and Finance 1, no. 9 (December).

2004. “The Relationship between Manufacturing Productivity and Goods Output." Federal Reserve Bank of New York Current Issues in Economics and Finance 10, no. 9 (August).

Williamson, Stephen D. 2008. Macroeconomics. 3rd ed. Boston, Mass.: Pearson.

\section{ABOUT THE AUTHORS}

Bart Hobijn is a research advisor in the Economic Research Department of the Federal Reserve Bank of San Francisco; Charles Steindel is a senior vice president in the Macroeconomic and Monetary Studies Function of the Federal Reserve Bank of New York.

Current Issues in Economics and Finance is published by the Research and Statistics Group of the Federal Reserve Bank of New York. Linda Goldberg and Charles Steindel are the editors.

The views expressed in this article are those of the authors and do not necessarily reflect the position of the Federal Reserve Bank of New York or the Federal Reserve System. 